\title{
Maternal congenital complete heart block in pregnancy: a rare case report
}

\author{
Reena Sood $^{1}$, Harmandeep Kaur ${ }^{1 *}$, Gaurav Mohan ${ }^{2}$, Madhu Nagpal ${ }^{1}$
}

\begin{abstract}
${ }^{1}$ Department of Obstetrics and Gynecology, Sri Guru Ramdas Institute of Medical Sciences and Research, Vallah, Sri Amritsar, Punjab, India

${ }^{2}$ Department of Medicine, Sri Guru Ramdas Institute of Medical Sciences and Research, Vallah, Sri Amritsar, Punjab, India
\end{abstract}

Received: 15 June 2020

Accepted: 08 July 2020

\section{*Correspondence:}

Dr. Harmandeep Kaur,

E-mail: drravjot09@gmail.com

Copyright: ( ) the author(s), publisher and licensee Medip Academy. This is an open-access article distributed under the terms of the Creative Commons Attribution Non-Commercial License, which permits unrestricted non-commercial use, distribution, and reproduction in any medium, provided the original work is properly cited.

\begin{abstract}
Complete heart block comprises complete absence of AV conduction - none of the supraventricular impulses are conducted to the ventricles. Perfusing rhythm is maintained by a junctional or ventricular escape rhythm. Typically, the patient will have severe bradycardia with independent atrial and ventricular rates. The incidence is 1 in 15,000 to 20,000 live births. Authors present the case report of a primigravida, aged 30 years who presented with amenorrhoea of 35 weeks. She was diagnosed as complete heart block by cardiologist. She had no history of syncopal attacks during childhood or antenatal period. She had a heart rate of 50-52 bpm. ECG showed ventricular escape rhythm with narrow QRS complexes. Echocardiography showed no structural defects. Her elective LSCS was done at 39 weeks after consultation with cardiologist. Patient underwent temporary pacemaker insertion just prior to surgery and she delivered a healthy female baby of weight $3 \mathrm{~kg}$ with Apgar 9/10 at 5 mins. She remained asymptomatic during the postoperative period and pacemaker was removed after 30 hours. She was discharged under satisfactory condition on day 6. Patient was counselled for follow up with cardiologist. This case lays emphasis on proper history taking, vitals monitoring, early recognition of undiagnosed cardiac disorders and team work for good maternal and fetal outcome
\end{abstract}

Keywords: AV block, Bradycardia, Congenital heart block, Pregnancy, Syncope

\section{INTRODUCTION}

Complete heart block (CHB) comprises complete absence of AV conduction-none of the supraventricular impulses are conducted to the ventricles. Perfusing rhythm is maintained by a junctional or ventricular escape rhythm. Alternatively, the patient may suffer ventricular standstill leading to syncope (if self-terminating) or sudden cardiac death (if prolonged).

Typically, the patient will have severe bradycardia with independent atrial and ventricular rates, i.e. AV dissociation. The incidence of complete heart block is estimated to be 1 in 15,000 to 20,000 live births. ${ }^{1}$ It can be congenital or acquired. However, the congenital variety is seen during pregnancy as the acquired type usually presents after 50 years of age. ${ }^{2}$

\section{CASE REPORT}

Authors present the case of a primigravida, aged 30 years who presented to the OPD with amenorrhea of 35 weeks. She had persistent bradycardia on examination. She was advised ECG and cardiologist opinion. She was diagnosed as a case of CHB. She had no past history of syncopal attacks during the childhood or antenatal period. She was doing routine household work during pregnancy without any complaints and was not performing any exercise or strenuous activity. Her general physical examination was normal apart from bradycardia with a 
heart rate of $50 \mathrm{bpm}$. Fundal height was corresponding to the period of amenorrhea. Fetal heart rate was 120-124 bpm, regular. ECG showed typical ventricular escape rhythm with narrow QRS complexes (Figure 1). Echocardiography showed no structural defects.

She was advised temporary pace making at the time of childbirth by cardiologist. Her elective LSCS was planned at 39 weeks after consultation with cardiologist. Temporary pacemaker insertion through transfemoral route was done prior to LSCS and a heart rate of $78 \mathrm{bpm}$ was set.

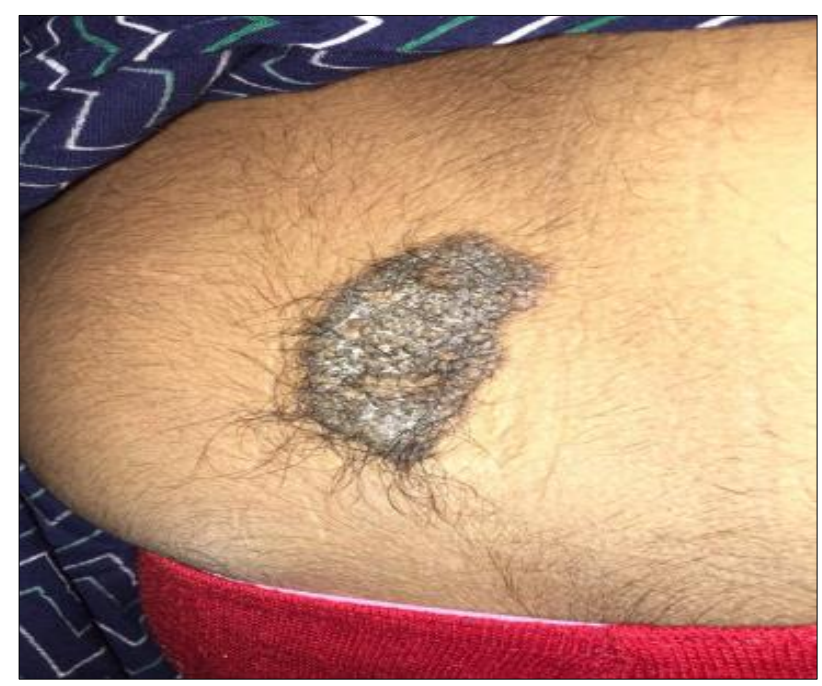

Figure 1: Hairy nevus on back of the patient.

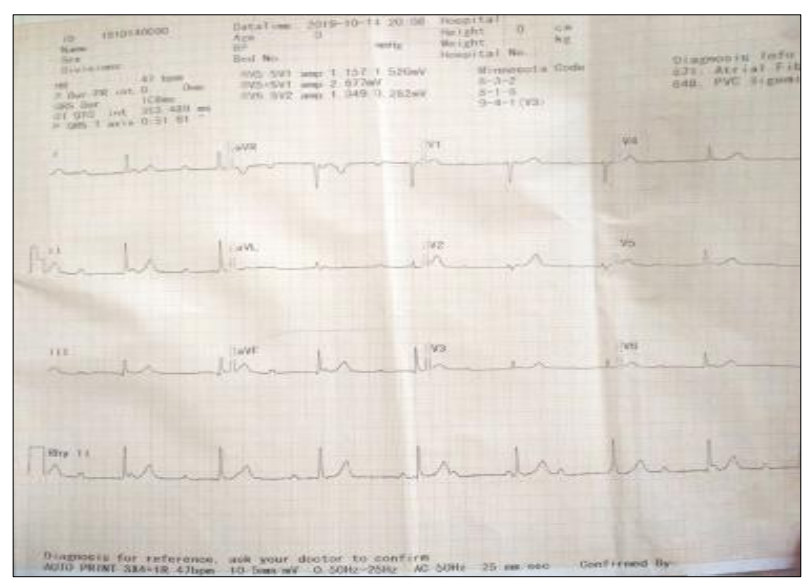

Figure 2: ECG ventricular escape rhythm.

As the patient had a hairy nevus on the back, general anesthesia was given (Figure 2). She delivered a healthy female baby with Apgar 9/10 at 5 mins weighing $3 \mathrm{~kg}$.

The patient had an uneventful convalescence in the cardiac ICU and temporary pacemaker was removed after 30 hours. She was later shifted to gynae ward. She was discharged on day 6 postop in a satisfactory condition. She had an uneventful puerperium, was lactating and was advised further visit to the cardiologist for future management.

\section{DISCUSSION}

Isolated congenital CHB is relatively benign with narrow QRS complexes on ECG, and heart rate may increase with atropine or sympathomimetics. ${ }^{3}$ Fetomaternal outcome is mostly favorable in asymptomatic cases and in uncomplicated bradyarrhythmia's without any significant underlying heart disease. ${ }^{4,5}$ Rarely preterm birth and intrauterine growth restriction has been observed. In most cases, no neonatal heart block had been seen. Few asymptomatic women without pacemakers may present with sudden cardiac death or heart failure during pregnancy, or may become symptomatic during labour due to Valsalva induced bradycardia. ${ }^{6}$

Significant bradyarrhythmia during labour and delivery have been reported in literature, which was attributed to increased sympathetic response at this stage or high uptake of regional anaesthesia. ${ }^{7}$ Thus, antenatal care warrants close surveillance by interdisciplinary teams. Drugs like labetalol (for preeclampsia) and nifedipine (for preterm labour) which are commonly used otherwise are contraindicated as they may aggravate heart block. Vaginal delivery is not contraindicated. Indication for caesarean section is for obstetric reasons and in those with intractable heart failure.

If general anesthesia is planned, then drugs with least depressing effect on the heart should be preferred like ketamine for induction of anesthesia. Agents like fentanyl and suxamethonium have been reported to cause bradycardia and asystole, so they should be avoided.

Need for pacemaker during pregnancy is debatable. Some favor managing asymptomatic patients without pacemaker with emergency arrangements for pacing available. ${ }^{8,9}$ Others suggest that temporary pacing should be done in patients with atropine resistant bradycardia, first and second degree AV block and atrial fibrillation with low ventricular rate. ${ }^{10}$ As sometimes syncopal attacks could be life threatening, pacing should be done early in pregnancy as it may significantly reduce morbidity and mortality. ${ }^{11}$

Emergency drugs needed to increase the heart rate during sudden fall in rate or syncopal attack like atropine and isoproterenol should be kept at hand.

\section{CONCLUSION}

The importance of putting our hand on the patient's pulse can never be undermined as this led to the diagnosis of $\mathrm{CHB}$ in this case. Every syncope should be taken seriously as syncopal attacks in pregnancy can be easily attributed to supine hypotension and ignored. 
This condition can be completely asymptomatic during pregnancy and diagnosed only when the patient comes in contact with the health facilities. ECG is an economical, reliable and easily available tool to diagnose such a grave condition. Once diagnosed, it needs a multidisciplinary approach for management involving obstetrician, cardiologist and anesthesiologist.

\section{Funding: No funding sources}

Conflict of interest: None declared

Ethical approval: Not required

\section{REFERENCES}

1. Perloff JK. The clinical recognition of congenital heart disease. Philadelphia: Elsevier; 2003:6.

2. Baghel K, Mohsin Z, Singh S, Kumar S, Ozair M. Pregnancy with complete heart block. J Obstet Gynecol India. 2016;66(Suppl 2):623-5.

3. Kumar AU, Sripriya R, Parthasarathy S, Ganesh B A, Ravishankar M. Congenital complete heart block and spinal anaesthesia for caesarean section. Indian $\mathbf{J}$ Anaesth. 2012;56(1):72-4.

4. Suri V, Keepanasseril A, Aggarwal N, Vijayvergiya R, Chopra S, Rohilla M. Maternal complete heart block in pregnancy: analysis of four cases and review of management. J Obstet Gynecol Res. 2009;35(3):434-7.

5. Keepanasseril A, Maurya DK, Selvaraj R. Complete atrioventricular block in pregnancy: report of seven pregnancies in a patient without pacemaker. Case Reports. 2015;2015:bcr2014208618.

6. Hidaka N, Chiba Y, Fukushima K, Wake N. Pregnant women with complete atrioventricular block: perinatal risks and review of management. Pacing Clin Electrophysiol. 2011;34(9):1161-76.

7. Thaman R, Curtis S, Faganello G, Szantho GV, Turner MS, Trinder J, et al. Cardiac outcome of pregnancy in women with a pacemaker and women with untreated atrioventricular conduction block. Europace. 2011;13:859-63.

8. Modi MP, Butala B, Shah VR. Anaesthetic management of an unusual case of complete heart block for LSCS. Indian J Anaesth. 2006;50(1):43-4.

9. Hidaka N, Chiba Y, Kurita T, Satoh S, Nakano H. Is intrapartum temporary pacing required for women with complete atrioventricular block? An analysis of seven cases. BJOG. 2006;113(5):605-7.

10. Kharde VV, Patil VV, Dhulkhed VK, Divekar DS. A parturient with complete heart block for cesarean section. J Anaeth Clin Pharmacol. 2010;26:401-2.

11. Michaelson M, Jonzon A, Riesenfeld T. Isolated congenital complete atrioventricular block in adult life: a prospective study. Circulat. 1995;92(3):442-3.

Cite this article as: Sood R, Kaur H, Mohan G, Nagpal M. Maternal congenital complete heart block in pregnancy: a rare case report. Int J Reprod Contracept Obstet Gynecol 2020;9:3502-4. 